\title{
Use of the MLX 90164 sensor and the ThingSpeak platform for internet of things-based animal body temperature check
}

\author{
Ridi Arif ${ }^{1} *$, Okta Irviana Mu'minin ${ }^{2}$, Nenis Rahma Wulandari ${ }^{2}$, Koekoeh Santoso ${ }^{3}$, Dhani S \\ Wibawa $^{4}$ \\ ${ }^{1}$ Department of Animal Infectious Diseases and Veterinary Public Health, Faculty of Veterinary Medicine, IPB \\ University \\ ${ }^{2}$ Undergraduate Program, Faculty of Veterinary Medicine, IPB University \\ ${ }^{3}$ Department of Anatomy, Physiology, and Pharmacology, Faculty of Veterinary Medicine, IPB University \\ ${ }^{4}$ Surfactant and Bioenergy Research Center, IPB University
}

\begin{abstract}
The MLX 90614 sensor is an IR sensor used to measure temperature without contact. This sensor can measure the object's temperature and ambient temperature in the range of $-40{ }^{\circ} \mathrm{C}-125{ }^{\circ} \mathrm{C}$. These sensors are widely used in areas such as room temperature measurement, machine temperature, ambient temperature, and body temperature. The MLX 90614 sensor is not yet fully usable directly to perform temperature measurements due to the program's simple defaults so that the measurement results are inaccurate. Therefore, optimization is needed to increase the precision value of the body's internal temperature estimation using this sensor. The method carried out in this study use 6 experimental sheep. Temperature checks are performed through a contact thermometer and compared to non-contact checks by MLX 90614 sensors. Results showed the average temperature of the contact thermometer was $39.28 \pm 0.09^{\circ} \mathrm{C}$ while the MLX sensor yield was $35.78 \pm 1.38^{\circ} \mathrm{C}$. The average temperature difference was $3.5 \pm 1.48^{\circ} \mathrm{C}$. The results showed that the temperature difference correction factor needs to be included in the script code when running MLX 90614 sensor. The results of temperature checks by the sensor can be sent directly in real time to the ThingSpeak platform so that the results can be stored and accessed in different places easily. The use of MLX 90614 sensor combined with IoT concept using ThingSpeak can facilitate the process of non-contact body temperature check, and also make the data can be accessed dan stored easily.
\end{abstract}

Keywords:

body temperature, animal, MLX 90164, ThingSpeak, IoT

\section{- INTRODUCTION}

Body temperature is one of the important physiological parameters in animals. Body temperature can describe the metabolism process that is running lancer or there is a disturbance (Morrison 2016). When the body temperature is higher than normal range it can be an indication of an increasing metabolism process due to an infection. The high temperatures will usually be corrected to the to the normal range by homeostasis system because if the body temperature continues in high conditions can be fatal (Tansey \& Christopher 2015; Osilla et al. 2020). Due to the importance of these temperature parameters, at each physical examination will always be included the results of the body temperature check. Body temperature checks are also routinely carried out in patients to monitor the progress of his condition.

The temperature body measurement with non-contact method was usually use in human, form example in body temperature check to prevent spread out of Covid-19 (Costanzo \& Flores 2020). In other hand the temperature screening in animal patients is still carried out manually through the contact thermometer. In fact, the examination contact and Internet of Things-based body temperature checking tool is very possible. One of the non-contact temperature sensors that can be used is MLX 90614. This is infrared sensor that can measure temperature without contact (Ahmed \& Abdullah 2020). This sensor can be combined with the concept of Internet of Things (IoT). Through this method, temperature checks in patients can be done effectively, efficiently, and do not cause stress in animals. On the other hand, the performance of the MLX 90614 sensor needs to be checked for accuracy before its use for body temperature check in animals. This study aims to find correction value so that MLX 90614 sensor can be used to check body temperature in animal with combine to IoT concept.

\section{- MATERIAL AND METHODE}

The tools used include MLX 90614 infrared temperature sensor, contact thermometer, Arduino microcontroller,

Received: 21-04-2021 | Revised: 15-05-2021 | Accepted: 19-05-2021 (C) 2021 CC-BY-SA. This is an Open Access article that is distributed under the terms of Creative Commons Attribution ShareAlike 4.0 International License (https://creativecommons.org/licenses/by-sa/4.0/). 
breadboard, ESP 8266 module, jumper wire, laptop, and Arduino IDE software. And then we use as much as 6 sheep for experimental animal. The MLX 90614 sensor to be connected to the microcontroller and installed using the default code. The measurement using a contact thermometer were used as a control. The temperature measurement using MLX 90614 sensor compared to contact thermometer and calculated the difference. Furthermore, the MLX 90614 sensor was also connected to the ESP 8266 module for the prototype of the IoT device. The scanned temperature was then sent in real-time via the ThingSpeak Platform IoT.

\section{- RESULT AND DISCUSSION}

The results of temperature measurement using MLX 90614 IR sensor and compared to contact thermometer are presented in Table 1. The temperature of the sheep used in this study seemed normal at about $39.28{ }^{\circ} \mathrm{C}$. Normal temperatures for sheep range from 38.8 to $39.9^{\circ} \mathrm{C}$ (Merck Vet Manual 2015). The results of measurement of the MLX 90614 sensor compared to the thermometer contacts showed significantly different values, the results of the MLX 90614 sensor $35.78 \pm 1.38{ }^{\circ} \mathrm{C}$ and thermometer contact $39.28 \pm 0.10$ ${ }^{\circ} \mathrm{C}$. The average temperature difference was $3.50 \pm 1.48^{\circ} \mathrm{C}$.

Table 1. The comparison of temperature measurement using MLX 90614 sensor and contact thermometer $\left({ }^{\circ} \mathrm{C}\right)$

\begin{tabular}{|cccc|}
\hline \multirow{2}{*}{ Trial } & \multicolumn{2}{c|}{ Sensor Type } & Difference \\
\cline { 2 - 3 } & $\begin{array}{c}\mathbf{M L X} \\
\mathbf{9 0 6 1 4}\left({ }^{\circ} \mathbf{C}\right)\end{array}$ & $\begin{array}{c}\text { Contact } \\
\text { Thermometer }\left({ }^{\circ} \mathbf{C}\right)\end{array}$ & \\
\hline Sheep 1 & 36.29 & 39.2 & 2.91 \\
Sheep 2 & 37.21 & 39.2 & 1.99 \\
Sheep 3 & 35.67 & 39.3 & 3.63 \\
Sheep 4 & 37.19 & 39.2 & 2.01 \\
Sheep 5 & 34.03 & 39.4 & 5.37 \\
Sheep 6 & 34.29 & 39.4 & 5.11 \\
\hline Average & $35.78 \pm 1.38^{\mathrm{b}}$ & $39.28 \pm 0.10^{\mathrm{a}}$ & $3.50 \pm 1.48$ \\
\hline
\end{tabular}

Note: different superscript show significant differences $(p<0.05)$

The results of the measurement using a contact thermometer showed a low deviation value (Table 1). This indicates that measurement using a contact thermometer provides accurate results. The result was accurate because the sensor area on the contact thermometer directly touches to the mucosa of the body so that all the heat from the mucosa can be transferred to the thermometer sensor.

On the other hand, the MLX 90614 IR sensor provides a lower temperature value of $3.5{ }^{\circ} \mathrm{C}$ and also has a higher deviation of approximately $1.38{ }^{\circ} \mathrm{C}$. This is due to the distance and free space between the sensor and the mucosal surface that releases heat. The presence of distances causes some heat to release into the air and there is an influence on the ambient temperature read by the MLX 90614 sensor. Therefore there needs to be a correction by entering the temperature difference of $3.50 \pm 1.48{ }^{\circ} \mathrm{C}$ in the MLX 90614 code script before uploading the program.

Furthermore, the construction of the Internet of Things prototype on the MLX 90614 temperature check device was carried out by connecting the microcontroller with the ESP 8266 wifi module (Parida et al. 2019). The module will automatically send the results of temperature measurement by sensors to the cloud via the IoT platform. One of the free IoT platforms that are easy and often used in the world of research is thingspeak.com (Pasha 2016). Thingspeak.com as IoT platform has some menu and tools that enough to record and analyze the data (Ray 2016). On the thingspeak.com website, the temperature data by MLX 90614 will be saved and the data will be updated automatically. The data recorded on thingspeak.com can also be accessed more easily through the ThingView application opened through a smartphone.

\section{- CONCLUSION}

The MLX 90614 sensor can be used for non-contact temperature checks on animals. To get accurate results, correction factor needs to be entered in code script before running MLX sensor. MLX 90614 sensor inspection data can be sent to IoT thingspeak.com platform so it can be easily stored and accessed.

\section{- AUTHOR INFORMATION}

\section{Corresponding author}

*RA: ridiarif88@apps.ipb.ac.id

Department of Animal Infectious Diseases and Veterinary Public Health, Faculty of Veterinary Medicine, IPB University, Jalan Agatis Kampus IPB Dramaga, Bogor, 16680, West Java INDONESIA

\section{- ACKNOWLEDGMENT}

The author is grateful to the Directorate General of Higher Education, Ministry of Research, Technology, and Higher Education for providing grants through the 2020 Higher Education Leading Research scheme no 2761/IT3.L1/PN/2020.

\section{- REFERENCES}

Ahmed A, Abdullah MN. 2020. Design of a contactless body temperature measurement system using Arduino. Indonesian Journal of Electrical Engineering and Computer Science. 19(3):1251-1258.

Costanzo S, Flores A. 2020. A non-contact integrated body ambient temperature sensors platform to contrast COVID-19. Electronics. 9:1-17.

Merck Veterinary Manual. 2015. www.merckvetmanual.com/specialsubjects/reference-guides/normal-rectal-temperature-ranges $[12 / 01 / 21]$

Morrison SF. 2016. Central control of body temperature. F1000 Faculty Rev-880. DOI: 10.12688/f1000research.7958.1

Osilla EV, Jennifer L, Marsidi, Sharma S. 2020. Physiology, Temperature Regulation. StatPearls [Internet] https://www.statpearls.com/ArticleLibrary/viewarticle/30050

Parida D, Behera A, Naik JK, Pattanaik S, Nanda RS. 2019. Real-time environment monitoring system using ESP8266 and ThingSpeak on internet of things platform. In2019 International Conference on Intelligent Computing and Control Systems (ICCS) 2019 May 15 (pp. 225 229). IEEE.

Pasha S. Thingspeak Based Sensing and Monitoring System for IoT with Matlab Analysis. International Journal of New Technology and Research. 2016. 2(6):19-23

Ray PP. 2016. A survey of IoT cloud platforms. Future Computing and Informatics Journal. 1(1-2):35-46.

Tansey SA, Christopher DJ. 2015. Recent Advances in thermoregulation. Advances in Physiology Education. 39(3):139-148. 